\title{
QUALITY OF LIFE IN VITILIGO PATIENTS AND ITS RELATION TO VARIOUS VARIABLES IN DUHOK, KURDISTAN REGION, IRAQ
}

\author{
ZEYAD S. AL-DABBAGH, MBCHB, FCABMS, FJMC*
}

\section{Submitted 5 May 2019; accepted 8 September 2019}

\begin{abstract}
Background: Background and aim: Studies, mainly in developed countries, have found a negative impact of the disease on the Quality of Life (QoL). This was affected by different socio-economic factors and by clinical aspects of the disease. The aim of the present study is to measure the impact of vitiligo on the QoL among patients and to investigate its relation to socio-demographic and clinical factors, in Duhok, Kurdistan Region, Iraq.

Patients and methods: A cross-sectional hospital-based study was conducted on 143 patients aged 16 years and above diagnosed to have vitiligo by a consultant dermatologist. All available patients to the investigator in the outpatient dermatology unit at a tertiary care hospital were asked to participate. An oral consent was obtained then a short questionnaire was filled for each patient regarding socio-demographic factors and clinical features of the disease. The QoL was estimated by using the Dermatology Life Quality Index (DLQI).

Results: The mean age \pm SD was $31.85 \pm 10.39$ years of which 76 were males, and 67 were females. The mean DLQI score was $6.67( \pm 4.81 \mathrm{SD})$. Only $13.3 \%$ reported no effect of the disease on their QoL while $39.9 \%, 16.8 \%$, and $30.1 \%$ of patients reported that the disease has small, moderate and very large negative effect, respectively on their QoL. There were no significant differences between the mean DLQI scores and gender, job, type and duration of the disease and current treatment status. The Qol was significantly more negatively affected among younger patients, those with higher education, married women, patient with darker skin type, and patients with hands, arms and feet involvement and those with a negative family history of vitiligo.

Conclusion: The disease has a negative impact on the QoL in the majority of patients. The dermatologist should put an emphasis on the psychological problems of the disease among their patients during planning their future management course.
\end{abstract}

Duhok Med J 2020; 14 (1): 44-52

Keywords: Vitiligo Patients, Dermatologist, Duhok, Kurdistan Region, Iraq.

$\mathbf{V}$

itiligo is a common skin condition. It is pigmentary skin disorder with no physical impairment but with a significant psychological impact due to its disfiguring appearance. Globally the prevalence of the disease ranges from 0.4 to $2.0 \%{ }^{1-3}$.

Several studies have shown that patient's quality of life (QoL) is negatively affected by the disease. The majority of those studies, however, were conducted in developed countries, particularly in the U.S.A. and England ${ }^{3-5}$.

The Dermatology Life Quality Index (DLQI) $^{6}$ has been widely used in vitiligo as a specific QoL instrument ${ }^{4,7}$. This index showed that the QoL is affected by the disease. ${ }^{5,7}$ The negative impact has varied in different communities; and with different socio-demographic variables. There has been variation of the effect regarding gender and marital status. Some studies found no gender variation while others detected more impact on females than male $1,7,8$. Similarly married were found to have lower QoL in some studies, while singles were found to be more affected than married in other studies s,9,10. $^{7}$. Generally the negative impact was more

* Lecturer, Department of Medicine, University of Duhok College of Medicine, Duhok, Kurdistan Region, Iraq. Correspondence author: Zeyad Al-Dabbagh, zeyad.aldabbagh@gmail.com, Mobil+7507513373 
marked in young than in elderly, and patients with involvement of exposed sites. Moreover, depigmentation of dark skin people had enormous stigma than in white skin patients ${ }^{4,7,10}$.

The aim of this study is to assess the QoL of patients by using DLQI and to investigate its relation to sociodemographic and clinical factors, in Duhok, Kurdistan Region, Iraq.

\section{PATIENTS AND METHODS}

The study was approved by the scientific committee of Duhok college of Medicine. A cross-sectional study was conducted among patients attending the dermatology outpatient clinic of Azadi teaching hospital; during the period from 1st of January 2017 to $31^{\text {st }}$ of March 2018. All available patients aged 16 years and abovewith at least one vitiligo patch of whatever type diagnosed by consultant dermatologist were approached and oral consent was obtained from them to participate in the study.

A short questionnaire was arranged and filled by the investigator. The questionnaire included data about age, gender, marital status, job and education level. Also information was collected regarding type and duration of the disease, site involved, and treatment, type of patient skin and family history of the disease. The type of skin was classified according to the Fitzpatrick scale of classifying skin into six types according to the intensity of color from blond to dark ${ }^{11}$.
The quality of life was assessed by using the Arabic version of Dermatology Life Quality Index (DLQI). Assistant in understanding questions was given, if needed. The DLQI scoring used according to the manual as ${ }^{6,12}$ :

$0-1$ : no effect on patient's life

2-5: small effect on patient's life

6-10: moderate effect on patient's life

11-20: very large effect on patient's life

21-30: extremely large effect on patient's life

In the analysis of correlation with different variable, the scoring was combined into 2 categories as small/ no effect and moderate/ large effect.

The statistical package for social sciences (SPSS), version 24 wasused for data entry and analysis. Data was summarized using percentages and counting for categorical variables, the mean and standard deviation for continues variables. The $\mathrm{X}^{2}$ and Fisher exact test, when indicated, were used for assessing statistical differences between proportions, and $\mathrm{P}$-value $\leq 0.05$ was considered significant.

\section{RESULTS}

Table 1 shows that out of the 143 patients included in the study 76 were males and 67 were females. About three quarter aged less than 40 years, with more than one third were in the age group 21-30 years. The mean age was 31.85 years ( \pm 10.39SD); with an age range of 16-59 years.

Table 1. Age-sex distribution of the vitiligo patients

\begin{tabular}{lcccccc}
\hline \multirow{2}{*}{ Age in years } & \multicolumn{2}{c}{ Male } & \multicolumn{2}{c}{ Female } & \multicolumn{2}{c}{ Total } \\
\cline { 2 - 7 } & No. & \% & No. & \% & No. & \% \\
\hline$\leq 20$ & 16 & 21.1 & 8 & 11.9 & 24 & 16.8 \\
$21-30$ & 27 & 35.5 & 26 & 38.8 & 53 & 37.1 \\
$31-40$ & 18 & 23.7 & 16 & 23.9 & 34 & 23.8 \\
$\geq 41$ & 15 & 19.7 & 17 & 25.4 & 32 & 22.4 \\
\hline Total & 76 & 100.0 & 67 & 100.0 & 143 & 100.0 \\
\hline $\mathrm{P}=0.499$ & & & & &
\end{tabular}


The study found that the mean DLQI score was $6.67( \pm 4.81 \mathrm{SD})$. Table 2 shows that in $13.3 \%, 39.9 \%, 16.8 \%$, and $30.1 \%$ of patients the disease has either no effect, small, moderate and very large effect respectively on their QoL. None of the patients reported an extremely large effect of vitiligo on QoL.

$\begin{aligned} & \text { Table 2. Distribution of the patients according to } \\
& \text { DLQI scores }\end{aligned}$
\begin{tabular}{lcc}
\hline DLQI scores & No. & $\%$ \\
\hline No effect (0-1) & 19 & 13.3 \\
Small effect (2-5) & 57 & 39.9 \\
Moderate effect (6-10) & 24 & 16.8 \\
Very large effect (11-20) & 43 & 30.1 \\
\hline Extremely large effect & 0 & 0.0 \\
\hline Total & 143 & 100.0 \\
\hline
\end{tabular}

Table 3 revealsthat the moderate to severe negative effect on the patient's QoL was significantly higher among younger in comparison to older patients, singles in comparison to married women, and among those with secondary and higher education in comparison to patients with low education. Table 3 also shows that gender and job have no significant effect on QoL among vitiligo patients.

\begin{tabular}{|c|c|c|c|c|c|c|c|}
\hline & 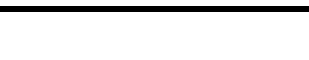 & 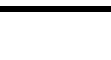 & I & $\overline{Q I}$ & & & \\
\hline \multirow{2}{*}{\multicolumn{2}{|c|}{ Socio-demographic factors }} & \multicolumn{4}{|c|}{$\begin{array}{ll}\text { Moderate to large } \\
\end{array}$} & \multirow{3}{*}{ Total no. } & \multirow{3}{*}{$\mathbf{P}$} \\
\hline & & \multicolumn{2}{|c|}{ No to small effect } & \multicolumn{2}{|c|}{ effect } & & \\
\hline & & No. & $\%$ & No. & $\%$ & & \\
\hline \multirow[t]{4}{*}{ Age in years } & $\leq 20$ & 6 & 25.0 & 18 & 75.0 & 24 & \multirow{4}{*}{0.008} \\
\hline & $21-30$ & 33 & 62.3 & 20 & 37.7 & 53 & \\
\hline & $31-40$ & 16 & 47.1 & 18 & 52.9 & 34 & \\
\hline & $\geq 41$ & 21 & 65.6 & 11 & 34.4 & 32 & \\
\hline \multirow[t]{2}{*}{$\operatorname{Sex}$} & Male & 38 & 50.0 & 38 & 50.0 & 76 & \multirow{2}{*}{0.422} \\
\hline & Female & 38 & 56.7 & 29 & 43.3 & 67 & \\
\hline \multirow[t]{2}{*}{ Job } & Not employed & 41 & 47.7 & 45 & 52.3 & 86 & \multirow{2}{*}{0.107} \\
\hline & Employed & 35 & 61.4 & 22 & 38.6 & 57 & \\
\hline \multirow[t]{4}{*}{ Education } & Illiterate & 12 & 75.0 & 4 & 25.0 & 16 & \multirow{4}{*}{0.002} \\
\hline & Primary & 25 & 73.5 & 9 & 26.5 & 34 & \\
\hline & Secondary & 24 & 38.1 & 39 & 61.9 & 63 & \\
\hline & University \& above & 15 & 50.0 & 15 & 50.0 & 30 & \\
\hline \multirow{3}{*}{$\begin{array}{l}\text { Marital } \\
\text { status }\end{array}$} & Single & 9 & 15.8 & 48 & 84.2 & 57 & \multirow{3}{*}{$<0.001$} \\
\hline & Married & 64 & 77.1 & 19 & 22.9 & 83 & \\
\hline & Widowed & 3 & 100.0 & 0 & 0.0 & 3 & \\
\hline Total & & 76 & 53.1 & 67 & 46.9 & 143 & \\
\hline
\end{tabular}

Table 4 shows significantly more QoL impairment among patients with dark skin in comparison to those with fair skin type. Also the negative impact on the QoL was more significant among those with hands, arms and feet involvement in comparison to those with no involvement. No such significant association was observed regarding involvement of the face. Table 4 also reveals that impairment of QoL was significantly higher among patient with no family history of the disease. Finally table 
4 also shows no significant differences in

and type of the disease.

QoL regarding treatment status, duration

\begin{tabular}{|c|c|c|c|c|c|c|c|}
\hline & & \multicolumn{4}{|c|}{ DLQI } & \multirow{3}{*}{ Total no. } & \multirow{3}{*}{$\mathbf{P}$} \\
\hline \multirow[t]{2}{*}{ Clinical factor } & & \multicolumn{2}{|c|}{ No to low effect } & \multicolumn{2}{|c|}{$\begin{array}{c}\text { Moderate to severe } \\
\text { effect }\end{array}$} & & \\
\hline & & No. & $\%$ & No. & $\%$ & & \\
\hline \multirow[t]{4}{*}{ Skin type* } & 2 & 7 & 63.6 & 4 & 36.4 & 11 & \multirow{4}{*}{$<0.001$} \\
\hline & 3 & 29 & 37.7 & 48 & 62.3 & 77 & \\
\hline & 4 & 36 & 70.6 & 15 & 29.4 & 51 & \\
\hline & 5 & 4 & 100.0 & 0 & 0.0 & 4 & \\
\hline \multirow[t]{3}{*}{ Duration } & $<1$ year & 27 & 50.0 & 27 & 50.0 & 54 & \multirow{3}{*}{0.090} \\
\hline & $1-<5$ years & 33 & 64.7 & 18 & 35.3 & 51 & \\
\hline & $5+$ years & 16 & 42.1 & 22 & 57.9 & 38 & \\
\hline \multirow[t]{2}{*}{ Faces involved. } & Yes & 57 & 58.8 & 40 & 41.2 & 97 & \multirow{2}{*}{0.051} \\
\hline & No & 19 & 41.3 & 27 & 58.7 & 46 & \\
\hline \multirow[t]{2}{*}{ Hands involved. } & Yes & 40 & 43.5 & 52 & 56.5 & 92 & \multirow{2}{*}{0.002} \\
\hline & No & 36 & 70.6 & 15 & 29.4 & 51 & \\
\hline \multirow[t]{2}{*}{ Arms involved. } & Yes & 12 & 37.5 & 20 & 62.5 & 32 & \multirow{2}{*}{0.044} \\
\hline & No & 64 & 57.7 & 47 & 42.3 & 111 & \\
\hline \multirow[t]{2}{*}{ Feet involved. } & Yes & 9 & 19.1 & 38 & 80.9 & 47 & \multirow{2}{*}{$<0.001$} \\
\hline & No & 67 & 69.8 & 29 & 30.2 & 96 & \\
\hline \multirow[t]{2}{*}{ Family history } & Yes & 27 & 96.4 & 1 & 3.6 & 28 & \multirow{2}{*}{$<0.00$} \\
\hline & No & 49 & 42.6 & 66 & 57.4 & 115 & \\
\hline \multirow[t]{4}{*}{ Type of vitiligo } & Generalized & 34 & 54.8 & 28 & 45.2 & 62 & \multirow{4}{*}{0.153} \\
\hline & Focal & 34 & 52.3 & 31 & 47.7 & 65 & \\
\hline & Segmental & 0 & 0.0 & 4 & 100.0 & 4 & \\
\hline & Acrofacial & 8 & 66.7 & 4 & 33.3 & 12 & \\
\hline \multirow[t]{2}{*}{ Current treatment } & Yes & 31 & 50.8 & 30 & 49.2 & 61 & \multirow{2}{*}{0.631} \\
\hline & No & 45 & 54.9 & 37 & 45.1 & 82 & \\
\hline \multicolumn{2}{|l|}{ Total } & 76 & 53.1 & 67 & 46.9 & 143 & \\
\hline
\end{tabular}

* Skin types 1 and 6 were not seen among participants

\section{DISCUSSION:}

Vitiligo is an idiopathic acquired, depigmentary disorder of the skin. The disease has no physical impairment but is cosmetically disfiguring leading to stigma and psychological problems in daily life; particularly in dark skin patients.13The negative impact on the QoL has been attributed to lack of effective treatment, chronic and unpredictable course and chronicity of the disease. Several studies all over the world showed that vitiligo has a negative effect on the QoL ${ }^{14,15}$, and lower self-esteem and high prevalence of psychiatric morbidity as compared to the normal populations. ${ }^{7,16}$

The majority of studies on QoL in vitiligo have been conducted in developed countries, mainly in Britain and the USA with a limited number in developing countries $^{2,7}$.

Different methods have been used to measure the QoL among patients. The DLQI tool, which was developed in 1994, has been used in 80 countries for more than 40 different skin conditions. It can be simply conducted within a short period and has been proven to be one of the most 
specific QoL instruments which have been widely used in vitiligo. Moreover a strong correlation was found between the scores of the total Vitiligo specific QoL(VitiQoL) and DLQI ${ }^{15,17-19}$.

The mean age of the patients was 31.85 years. This was similar to other studies ${ }^{5}$.

The mean DLQI score was 6.18. This is relatively similar to a study conducted inIndia (6.86) and Belgium (4.95) ${ }^{4,10}$, but lower than that found in Saudi Arabia(14.72) and $\operatorname{Iran}(8.16){ }^{8,9}$. This is because QoL is an index with several dimensions affected by socio-cultural and behavioral factors. This is why it is always essential to measure QoL in different societies.

The study found that vitiligo affected the QoL in86.7\% of patients with only $13.3 \%$ reported no negative effect on their QoL. About 39.9\% reported small effect and $16.8 \%$ and $30.1 \%$ indicated that the disease had moderate and very large negative effect; while the extremely large effect was not detected among patients.A cross-sectional hospital-based study conducted in India on 100 patients similarlyshowed that $84 \%$ of the vitiligo patients had some effect on their QoL; with $47 \%$ suffered moderate to very large effect; 10 Other studies found relatively similar results ${ }^{7}$.

The study found that unmarried women had a significantly higher negative impact on their Qol in comparison to married women. Similar results have been reported in India, and authors suggested that it might be due to the concern that this might affect their marriage pathway ${ }^{10}$.

The study found no significant differences on QoL between males and females patients. Similar results have been found in other studies ${ }^{8,10}$. This might indicates that both genders are concerned about the impact of vitiligo on their QoL

The negative impact on the Qol was significantly higher among dark skin in comparison to light skin patients and among those with involvement of exposed parts of the body. Similar results have been found in other studies. ${ }^{7}$

A positive family history was found in about $20 \%$ of cases. Relatively similar results were reported in Turkey and Saudi Arabia. The study found that patients with positive family history had significantly less effect on the QoL in comparison with those with no family history of vitiligo. This is because social stigma might be milder if other family members are affected.

There was a significantly higher DLQI scores among patients with secondary and higher education in comparison to those with lower education. This might be due to more concern about the general look among educated persons. Similar results were reported in Saudi Arabia ${ }^{20}$.

In conclusion, and despite being a hospital based study, the results indicated clearly that vitiligo has a negative impact on the QoL in the majority of patients. This should carry a message to dermatologist to put more emphasis on the psychological problems as part of their future management plan.

\section{REFERENCES}

1. Sawant NS, Vanjari NA, Khopkar U. Gender Differences in Depression, Coping, Stigma, and Quality of Life in Patients of Vitiligo. Dermatol Res 
Pract. 2019 Apr 2; 2019: 6879412. https://doi.org/10.1155/2019/6879412.

2. Hedayat $\mathrm{K}$, Karbakhsh $\mathrm{M}$, Ghiasi M, Goodarzi A, Fakour Y, Akbari Z, et al. Quality of life in patients with vitiligo: a cross-sectional study based on Vitiligo Quality of Life index (VitiQoL). Health Qual Life Outcomes. 2016; 14: 86. https://doi.org/10.1186/s12955-0160490-y.19177700.

3. Silverberg NB. The epidemiology of vitiligo. Curr Derm Rep. 2015; 4: 36. https://doi.org/10.1007/s13671-0140098-6.

4. Kota RS, Vora RV, Varma JR, Kota SK, Patel TM, Ganjiwale J.Study on Assessment of Quality of Life and Depression in Patients of Vitiligo. Indian Dermatol Online J. 2019; 10(2): 153-157.

5. Ongenae K, Van Geel N, De Schepper S, Naeyaert JM. Effect of vitiligo on self-reported health-related quality of life.Br J Dermatol. 2005; 152(6):116572.

6. Finlay AY, Khan GK. https://www.cardiff.ac.uk/medicine/re sources/quality-of-life-questionnaires/ dermatology-life-quality-index.( date accessed 3, January, 2019)

7. Amer AA, Gao XH. Quality of life in patients with vitiligo: an analysis of the dermatology life quality index outcome over the past two decades. Int J Dermatol. 2016; 55(6): 608-14.

8. Al Robaee A A. Assessment of quality of life in Saudi patients with vitiligo in a medical school in Qassim province, Saudi Arabia. Saudi Med J. 2007; 28(9): 1414-7.
9. Dolatshahi

M, Ghazi

P, Feizy $\mathrm{V}$, Hemami MR. Life quality assessment among patients with vitiligo: comparison of married and single patients in Iran. Indian J Dermatol Venereol Leprol. 2008; 74 (6): 700. [cited 2019 June 3]; 74:700. Available from: http://www.ijdvl.com/text.asp?2 008/74/6/700/45141.

10. Mishra N, Rastogi MK, Gahalaut P, Agrawal S. Dermatology Specific Quality of Life in Vitiligo Patients and Its Relation with Various Variables: A Hospital Based Cross-sectional Study.J ClinDiagn Res. 2014; 8(6): YC01YC03. https://doi.org/10.7860/J CDR/2014/8248.4508.

11. Fitzpatrick TB. The Validity and Practicality of Sun-Reactive Skin Types I Through VI. Arch Dermatol. 1988; 124 (6):869-871.

12. Finlay AY and Khan GK. Dermatology Life Quality Index (DLQI): a simple practical measure for routine clinical use. Clin Exp Dermatol 1994; 19:210-216.

13. Pahwa P, Mehta M, Khaitan BK, Sharma VK, Ramam M. The psychosocial impact of vitiligo in Indian patients. Indian $\mathrm{J}$ Dermatol Venereol Lep rol. 2013; 79:679-85.

14. Belhadjali H, Amri M, Mecheri A, Doarika A, Khorchani H, Youssef M, et al. Vitiligo and quality of life: A case-control study. Ann Dermatol Venereol. 2007; 134:233-36.

15. CatucciBoza J, Giongo N, Machado P, Horn R, Fabbrin A, Cestari T. Quality of Life Impairment in Children and Adults with Vitiligo: A 
Cross-Sectional Study Based on

Dermatology-Specific and DiseaseSpecific Quality of Life Instruments. Dermatology. 2016; 232(5): 619-625.

16. Mattoo SK, Handa S, Kaur I, Gupta N, Malhotra R. Psychiatric morbidity in vitiligo: Prevalence and correlates in India. J Eur Acad Dermatol Venereol. 2002; 16:573-78.

17. Basra MKA, Fenech R, Gatt RM, Salek MS, Finlay A.Y. The Dermatology Life Quality Index 19942007: A comprehensive review of validation data and clinical results. $\mathrm{Br}$ J Dermatol. 2008; 159: 997-1035.

18. Catucci Boza J, Giongo N, Machado P, Horn R, Fabbrin A, CestariT. Quality of Life Impairment in Children and Adults with Vitiligo: A Cross-Sectional Study Based on Dermatology-Specific and Disease-
Specific Quality of Life Instruments. Dermatology. 2016; 232(5):619-625.

19. Basra MKA, Fenech R, Gatt RM, Salek MS, Finlay A.Y. The Dermatology Life Quality Index 19942007: A comprehensive review of validation data and clinical results. $\mathrm{Br}$ J Dermatol. 2008; 159:997-1035.

20. Bin Saif GA, Al-Balbeesi AO, Binshabaib R, Alsaad D, Kwatra SG, Alzolibani AA, et al. Quality of life in family members of vitiligo patients: a questionnaire study in Saudi Arabia. Am J Clin Dermatol. 2013 Dec; 14(6): 489-95 


\section{هوخته}

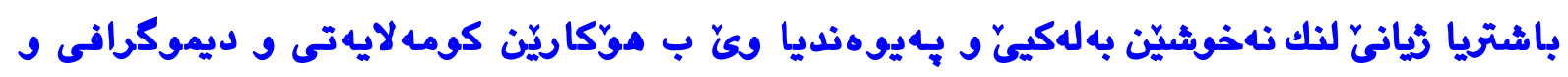
تهختهبهندى ل دهوك - مهريما كوردستانيّ - عيراق

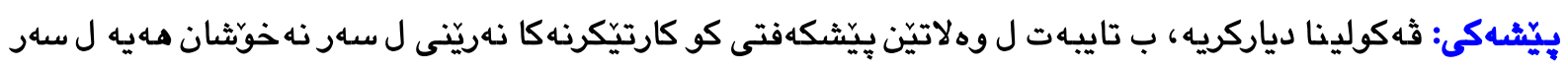

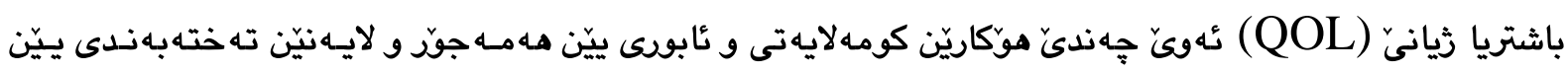
نه خوّثيى كارليَكربوو.

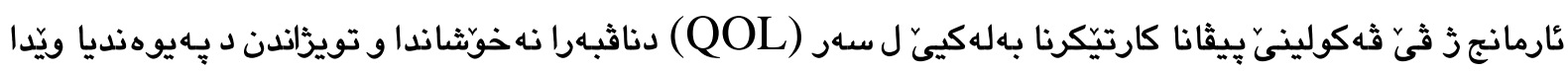

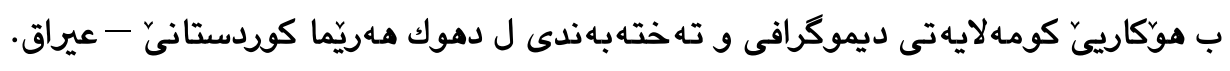

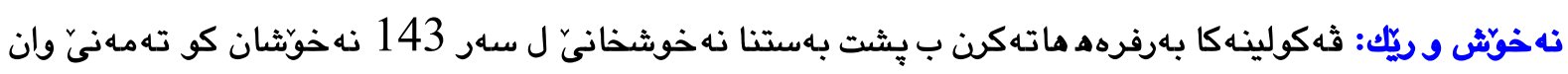

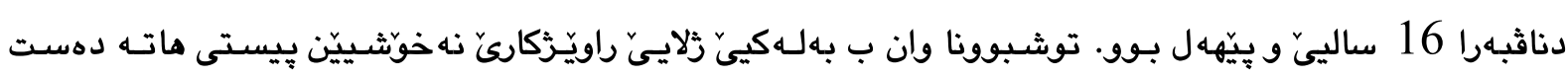

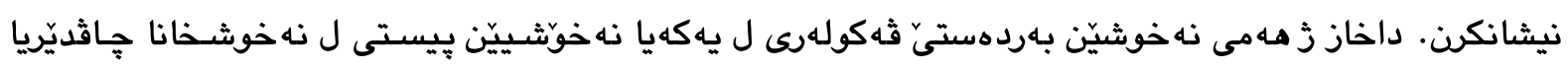

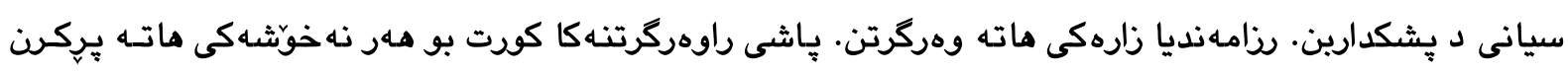

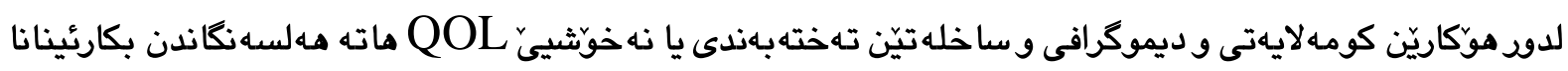

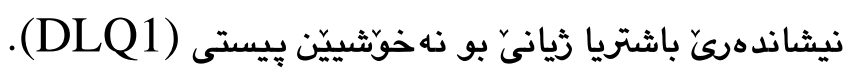

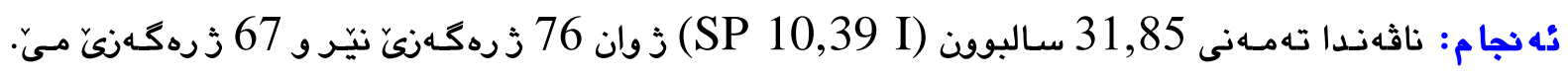

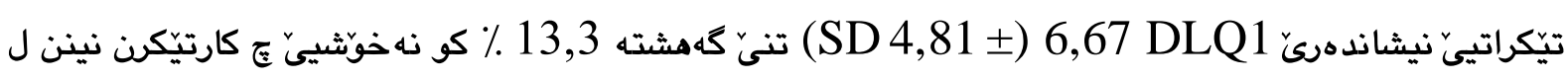

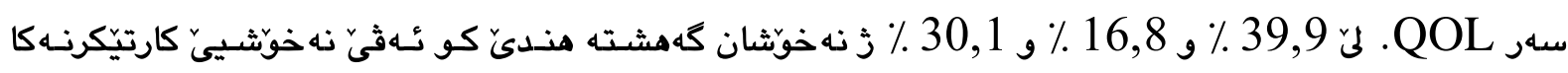

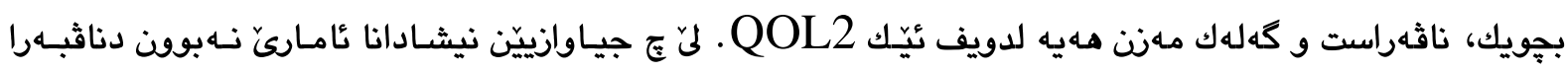

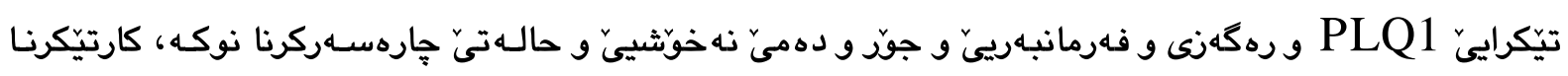

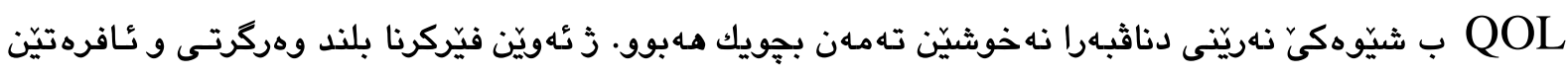

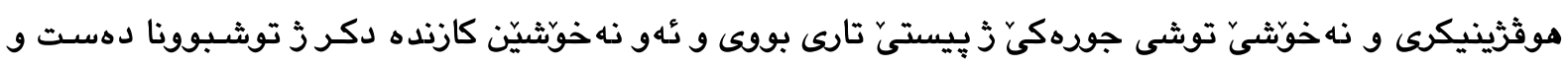

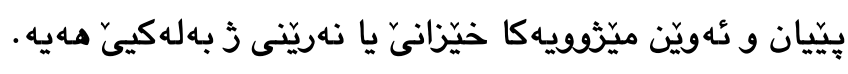

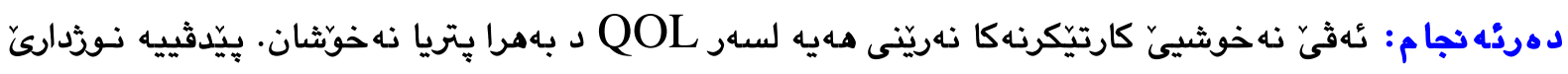

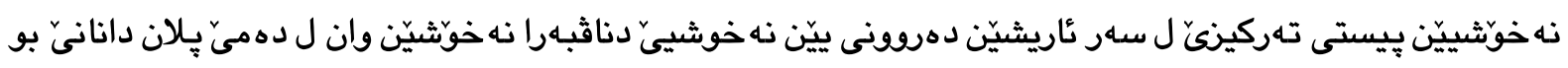
جارهسهركرنى 


\section{الخلاصة}

\section{جودة الحياة لاى مرضى البهاق وعلاقتها بالعوامل الاجتماعية والايموغرافية والسريرية في دهوك، إقليم كوردستان-العراق باق العية}

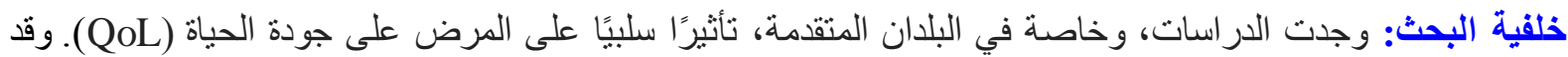

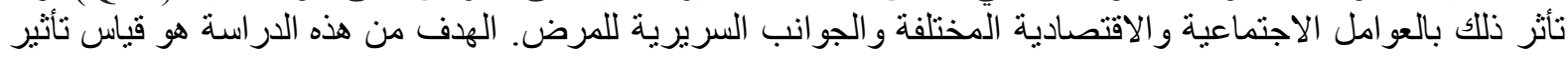

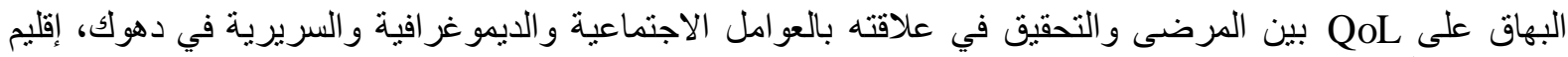
كوردستان العر اق.

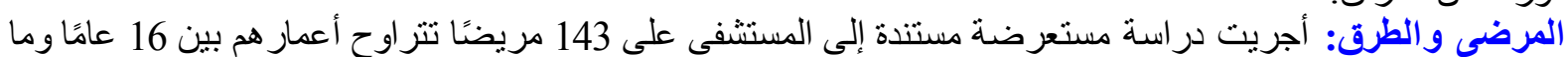

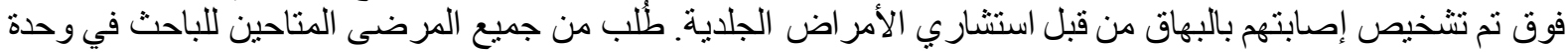

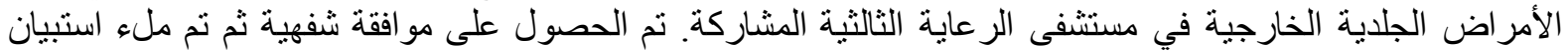

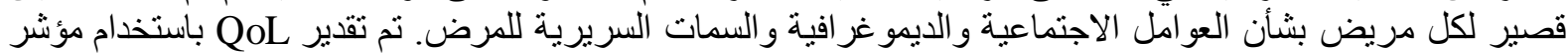
جودة الحياة للأمر اض الجلدية (DLQI).

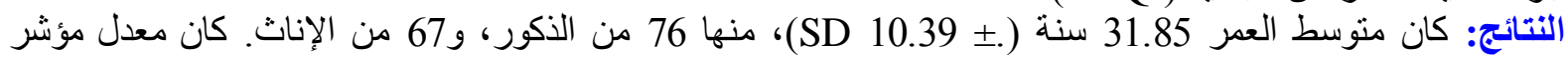

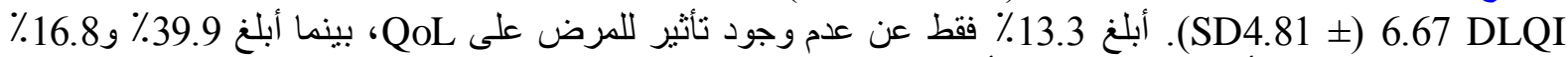

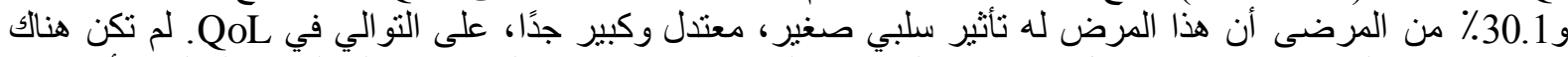

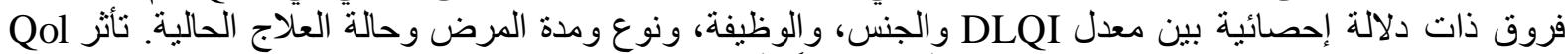

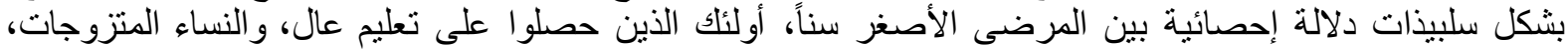

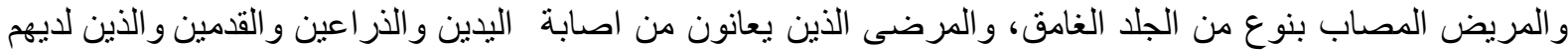

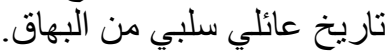
الاستنتجات: هذا المرض لهن تلأثنير سلبي على QoL في غالبية المرضى. يجب على طبيب الأمر اض الجلدية التركيز على المشكلات النفسية للمرض بين مرضاهم أثناء التخطيط للعلاج. 